CLINICAL STUDY

\title{
Gene expression of PPAR $\gamma$ and PGC-1 $\alpha$ in human omental and subcutaneous adipose tissues is related to insulin resistance markers and mediates beneficial effects of physical training
}

\author{
Karen Ruschke, Lauren Fishbein ${ }^{1,}$, Arne Dietrich ${ }^{2}$, Nora Klöting, Anke Tönjes, Andreas Oberbach, \\ Mathias Fasshauer, Jost Jenkner ${ }^{3}$, Michael R Schön ${ }^{3}$, Michael Stumvoll, Matthias Blüher and Christos S Mantzoros ${ }^{1}$ \\ Department of Medicine, Endocrinology/Diabetes, University of Leipzig, Liebigstrasse 20, 04103 Leipzig, Germany, ${ }^{1}$ Division of Endocrinology, Diabetes, \\ and Metabolism, Harvard Medical School, Beth Israel Deaconess Medical Center, 330 Brookline Avenue, ST 816, Boston, Massachusetts 02215, USA, \\ ${ }^{2}$ Department of Surgery, University of Leipzig, Leipzig, Germany and ${ }^{3}$ Städtisches Klinikum Karlsruhe, Clinic of Visceral Surgery, Karlsruhe, Germany \\ (Correspondence should be addressed to C S Mantzoros; Email: cmantzor@bidmc.harvard.edu, M Blüher; Email: bluma@medizin.uni-leipzig.de)
}

(K Ruschke and L Fishbein contributed equally to this work)

\begin{abstract}
Objective: Obesity and type 2 diabetes (T2D) are reaching epidemic proportions in Western societies, and they contribute to substantial morbidity and mortality. The peroxisome proliferator-activated receptor $\gamma(\operatorname{PPAR} \gamma)$ and PPAR $\gamma$ coactivator- $1 \alpha(\mathrm{PGC}-1 \alpha)$ system plays an important role in the regulation of efficient energy utilization and oxidative phosphorylation, both of which are decreased in obesity and insulin resistance.

Design and methods: We measured the metabolic parameters and the expression of PPAR $\gamma$ and PGC-1 $\alpha$ mRNA using quantitative real-time PCR in omental and subcutaneous (SC) adipose tissues in an observational study of 153 individuals as well as in SC fat and skeletal muscle in an interventional study of 60 subjects (20 each with normal glucose tolerance, impaired glucose tolerance, and T2D) before and after intensive physical training for 4 weeks.

Results: PPAR $\gamma$ and PGC-1 $\alpha$ mRNA expression in both fat depots as well as in skeletal muscle is associated with markers of insulin resistance and cardiovascular risk. PGC-1 $\alpha$ mRNA expression is significantly higher in SC fat than in omental fat, whereas PPAR $\gamma$ mRNA expression is not significantly different between these fat depots. Skeletal muscle and SC fat PPAR $\gamma$ and PGC-1 $\alpha$ mRNA expression increased significantly in response to physical training.

Conclusions: Gene expression of PPAR $\gamma$ and PGC-1 $\alpha$ in human adipose tissue is related to markers of insulin resistance and cardiovascular risk. Increased muscle and adipose tissue PPAR $\gamma$ and PGC-1 $\alpha$ expression in response to physical training may mediate the beneficial effects of exercise on insulin sensitivity.
\end{abstract}

European Journal of Endocrinology 162 515-523

\section{Introduction}

Obesity and type 2 diabetes (T2D), conditions of epidemic proportions in Western societies, are states of insulin resistance associated with increased fatty acid deposits in muscle as well as with inefficient energy utilization and oxidative phosphorylation (OXPHOS). Peroxisome proliferator-activated receptor $\gamma$ (PPAR $\gamma)$ acts as a transcription factor regulating the expression of several genes involved in metabolic pathways including energy expenditure and OXPHOS (1). $\operatorname{PPAR} \gamma$ is highly expressed in adipose tissue, where its activation with thiazolidinediones may alter fat distribution and adipocyte phenotype, and upregulates genes involved in fatty acid metabolism and triglyceride storage (1). Furthermore, PPAR $\gamma$ activation is associated with potentially beneficial effects on the expression and secretion of several molecules, including adiponectin, interleukin (IL)-6, tumour necrosis factor- $\alpha$, plasminogen activator inhibitor- 1 , monocyte chemoattractant protein-1, and angiotensinogen, as well as with a reduction in plasma nonesterified fatty acid supply (1).

PPAR $\gamma$ coactivator- $1 \alpha$ (PGC- $1 \alpha)$, identified as the first member of a small family of transcriptional coactivators, is a cofactor for the nuclear hormone receptor $\operatorname{PPAR} \gamma$ that is required for the adaptive thermogenic response to lower temperatures, and has been linked to tissue-specific metabolic pathways in the adaptive response to environmental and nutritional stimuli. Despite generally low expression in human white adipose tissue (2), PGC-1 $\alpha$ mRNA expression has been shown to be downregulated in white adipose tissue of insulin-resistant (3) and morbidly obese (4) subjects. 
The PGC- $1 \alpha$ gene is highly expressed in human skeletal muscle $(1,5)$, and insulin stimulation increases muscle expression of $P G C-1 \alpha$ (6). In addition, expression of $P G C-1 \alpha$ is induced by exercise through $5^{\prime}$-AMP-activated protein kinase (AMPK) and calcium, cytokines, and leptin (7). Expression of PGC-1 $\alpha$ in skeletal muscle is lower in patients with T2D and also in nondiabetic subjects with a positive family history of diabetes (8). Exercise studies using different training durations and intensities revealed heterogeneous results in physical exercise-induced changes with both increased (9-11) and unaffected (12-14) PGC-1 $\alpha$ expression in skeletal muscle. It still remains unknown, however, whether PGC- $1 \alpha$ expression in adipose tissue changes with exercise. Moreover, PGC-1 $\alpha$ and PPAR $\gamma$ mRNA expression changes in muscle and fat have not been systematically studied in relation to exerciseinduced changes of anthropometric and metabolic parameters.

Because exercise improves insulin resistance and the PPAR $\gamma$ pathway is associated with increasing the OXPHOS pathway, we hypothesized that PGC- $1 \alpha$ and PPAR $\gamma$ expression would be upregulated in muscle and downregulated in adipose tissue with intensive exercise. To this end, we first explored the associations of PPAR $\gamma$ and $P G C-1 \alpha$ expression in visceral and subcutaneous (SC) adipose tissues with metabolic parameters and insulin sensitivity in paired samples of omental and SC adipose tissues from 153 individuals with a wide range of obesity, fat distribution, insulin sensitivity and glucose tolerance in the context of a cross-sectional study. We then examined, in the context of an interventional study, the effect of 4 weeks of intensive exercise on PPAR $\gamma$ and PGC- $1 \alpha$ mRNA expression in both skeletal muscle and SC adipose tissue in 60 subjects with various degrees of glucose tolerance.

\section{Research design and methods}

\section{Cross-sectional study}

Paired samples of visceral and SC adipose tissues were obtained from 153 consecutively enrolled Caucasian men $(n=75)$ and women $(n=78)$ who underwent open abdominal surgery for gastric banding, cholecystectomy, weight reduction surgery, or explorative laparotomy. Inclusion and exclusion criteria have been described previously (15). In brief, patients were included if they fulfilled the following criteria: i) absence of any acute or chronic inflammatory disease as determined by a leukocyte count $>7000 \mathrm{Gpt} / \mathrm{l}$, C-reactive protein $>5.0 \mathrm{mg} / \mathrm{dl}$, or clinical signs of infection; ii) undetectable antibodies against glutamic acid decarboxylase; iii) no medical history of hypertension, i.e. systolic blood pressure was $<140 \mathrm{mmHg}$ and diastolic blood pressure was $<85 \mathrm{mmHg}$; iv) no clinical evidence of either cardiovascular or peripheral arterial disease; v) no thyroid dysfunction; vi) no alcohol or drug abuse; vii) no pregnancy. Percent body fat was measured by dual-energy X-ray absorptiometry (DEXA), and abdominal visceral and SC fat areas were calculated using computed tomography (CT) scans as described previously (16). Visceral and SC fat areas were calculated using CT or magnetic resonance imaging scans at the level of L4-L5. A ratio of visceral to SC fat area $>0.5$ was used as a cut-off to define visceral and SC obesity groups. Samples of visceral and SC adipose tissues were immediately frozen in liquid nitrogen after explantation. Insulin sensitivity was assessed with the euglycemic-hyperinsulinemic clamp method and oral glucose tolerance test (OGTT) (16). With this, we identified 67 individuals with either T2D $(n=36)$ or impaired glucose tolerance (IGT, $n=31$ ). Three days before the OGTT, the patients documented a highcarbohydrate diet. The OGTT was performed after an overnight fast with $75 \mathrm{~g}$ standardized glucose solution (Glucodex Solution $75 \mathrm{~g}$, Merieux, Montreal, Quebec, Canada). Venous blood samples were collected at 0,60 , and $120 \mathrm{~min}$ for measurements of plasma glucose concentrations. Insulin sensitivity was assessed with the euglycemic-hyperinsulinemic clamp method as described previously (17). Basal blood samples were collected after an overnight fast, and plasma insulin, leptin and adiponectin, free fatty acids (FFAs), and cholesterol were assayed as described previously (17). The study was approved by the ethics committees at the University of Leipzig. All subjects gave written informed consent before taking part in the study.

\section{Exercise interventional study}

We studied 60 Caucasian men and women with no acute or chronic inflammatory disease, alcohol or drug abuse, or diabetic retinopathy or nephropathy. Based on the OGTT results, subjects were categorized into groups of normal glucose tolerance (NGT; $n=20,9$ males and 11 females), IGT ( $n=20,9$ males and 11 females), and T2D ( $n=20,11$ males and 9 females). All subjects were enrolled in $60 \mathrm{~min}$ of supervised physical training sessions 3 days per week as described previously (17). In brief, each training session included 20 min of biking or running, $20 \mathrm{~min}$ of swimming, and $20 \mathrm{~min}$ of warming up/cooling down periods. All subjects completed a graded bicycle ergometer test to volitional exhaustion and had maximal oxygen uptake measured with an automated open circuit gas analysis system at baseline. The highest oxygen uptake/min reached was defined as the maximal oxygen uptake $\left(\mathrm{VO}_{2} \max \right)$, and subjects subsequently trained at their individual submaximal heart rate using heart rate monitors. At baseline and after 4 weeks of training ( $48 \mathrm{~h}$ after the last training session), SC adipose tissue and blood samples were obtained in the fasting state, and DEXA analyses and measurements of anthropometric parameters were done. All baseline blood samples 
and tissue samples were collected between 0800 and $1000 \mathrm{~h}$ after an overnight fast. Skeletal muscle biopsies were obtained under local anesthesia from the right vastus lateralis muscle and were immediately frozen in liquid nitrogen (16).

\section{Analysis of PPAR $\gamma$ and PGC-1 $\alpha$ mRNA expression in adipose tissue and skeletal muscle}

Human PPAR $\gamma$ and PGC- $1 \alpha$ gene expression was measured by quantitative real-time (RT)-PCR in a fluorescent temperature cycler using the TaqMan assay, and fluorescence was detected on an ABI PRISM 7000 sequence detector (Applied Biosystems, Darmstadt, Germany), after an initial denaturation at $95^{\circ} \mathrm{C}$ for $10 \mathrm{~min}$, followed by 40 PCR cycles, each cycle consisting of $95{ }^{\circ} \mathrm{C}$ for $15 \mathrm{~s}, 60{ }^{\circ} \mathrm{C}$ for $1 \mathrm{~min}$, and $72{ }^{\circ} \mathrm{C}$ for $1 \mathrm{~min}$. The following primers were used: adipose tissue (detects PPAR $\gamma_{2}$ ): human PPAR $\gamma$ : AGG CGA GGG CGA TCT TGA CAG (sense) and GAT GCG GAT GGC CAC CTC TTT (antisense); skeletal muscle (detects PPAR $\gamma_{1}$ ): human PPAR $\gamma$ : AAA GAA GCC GAC ACT AAA CC (sense) and CTT CCA TTA CGG AGA GAT CC (antisense); human PGC-1 $\alpha$ : TGC CCT GGA TTG TTG ACA TGA (sense) and TTT GTC AGG CTG GGG GTA GG (antisense); and human 18s rRNA: TGC CAT GTC TAA GTA CGC ACG (sense) and TTG ATA GGG CAG ACG TTC GA (antisense). In addition, we measured mRNA expression of the PPAR $\gamma$ target genes lipoprotein lipase (LPL), hormone-sensitive lipase (HSL) and fatty acid synthase $(F A S N)$ as described previously $(18,19)$. Expression of PPAR $\gamma, P G C-1 \alpha, L P L, H S L, F A S N$, and $18 \mathrm{~s}$ RNA was quantified by using the second derivative maximum method of the Taqman Software (Applied Biosystems). Amplification of specific transcripts was confirmed by melting curve profiles at the end of each PCR. The specificity of the PCR was further verified by subjecting the amplification products to agarose gel electrophoresis.

\section{Statistical analysis}

Descriptive characteristics are expressed as mean \pm s.D. comparisons. These were calculated using one-way ANOVA with Bonferroni corrections for post-hoc tests. Nonparametric Spearman correlation coefficients were calculated to examine the cross-sectional associations of PPAR $\gamma$ and PGC-1 $\alpha$ with anthropometric and insulin resistance-related parameters. Analyses were performed first without adjustments and then by adjusting for age, gender, and either BMI, percent body fat or waist-to-hip ratio (WHR). For the interventional study, post-hoc comparisons of baseline and after-training measures, expressed as mean \pm s.D., were done using a paired $t$-test within groups of glucose tolerance (NGT, IGT, and T2D). Differences in change between groups in measurements were compared by a general linear model regression analysis with and without adjustments for BMI. Statistical analyses were performed using SPSS (SPSS, Inc., Chicago, IL, USA) and SAS (SAS Institute, Cary, $\mathrm{NC}, \mathrm{USA}$ ).

\section{Results \\ PPAR $\gamma$ and PGC-1 $\alpha$ mRNA expression in adipose tissue: cross-sectional study}

We present pairwise comparisons of descriptive characteristics of subjects who participated in both the crosssectional study $(n=153)$ and the exercise intervention study $(n=60)$ in Table 1 . We performed additional

Table 1 Descriptive and metabolic characteristics of peroxisome proliferator-activated receptor $\gamma$ (PPAR $\gamma$ ) and PPAR $\gamma$ coactivator- $1 \alpha$ from a cross-sectional study of $n=153$ subjects categorized as lean, subcutaneously (SC) obese, or viscerally obese and of $n=60$ subjects categorized in groups of normal glucose tolerance (NGT), impaired glucose tolerance (IGT), and type 2 diabetes (T2D) from separate exercise intervention trial at baseline.

\begin{tabular}{|c|c|c|c|c|c|c|}
\hline \multirow[b]{2}{*}{ Variable } & \multicolumn{3}{|c|}{ Cross-sectional study } & \multicolumn{3}{|c|}{ Exercise intervention study } \\
\hline & Lean & SC obese & Visceral obese & NGT & IGT & T2D \\
\hline$n$ & 58 & 58 & 37 & 20 & 20 & 20 \\
\hline Age & $50.2 \pm 15.7$ & $55.3 \pm 13.2$ & $64.4 \pm 11.6^{\ddagger, \|}$ & $32.8 \pm 11.0$ & $56.0 \pm 11.5^{\ddagger}$ & $53.1 \pm 6.7^{\ddagger}$ \\
\hline Male/female $(n)$ & $28 / 30$ & $28 / 30$ & $19 / 18$ & $9 / 11$ & $9 / 11$ & $11 / 9$ \\
\hline BMI $\left(\mathrm{kg} / \mathrm{m}^{2}\right)$ & $23.9 \pm 1.4$ & $35.9 \pm 6.8^{\ddagger}$ & $33.6 \pm 6.1^{\ddagger}$ & $24.3 \pm 1.5$ & $29.8 \pm 3.9^{\dagger}$ & $31.4 \pm 3.2^{\ddagger}$ \\
\hline WHR & $0.85 \pm 0.1$ & $1.05 \pm 0.1^{\ddagger}$ & $1.13 \pm 0.1^{\ddagger, \|}$ & $0.84 \pm 0.1$ & $1.21 \pm 0.2^{\ddagger}$ & $1.28 \pm 0.1^{\ddagger}$ \\
\hline Percent body fat (by DEXA) & $21.6 \pm 2.9$ & $41.1 \pm 19.5^{\ddagger}$ & $32.9 \pm 6.8^{\ddagger, 9}$ & $24.5 \pm 3.2$ & $35.0 \pm 8.3^{\ddagger}$ & $38.2 \pm 8.0^{\ddagger}$ \\
\hline Fasting plasma glucose $(\mathrm{mmol} / \mathrm{l})$ & $5.4 \pm 2.9$ & $5.9 \pm 1.4^{\dagger}$ & $5.8 \pm 1.0$ & $5.2 \pm 0.5$ & $5.7 \pm 0.6^{*}$ & $6.2 \pm 0.6^{\ddagger, \|}$ \\
\hline $\mathrm{HbA1c}(\%)$ & $5.3 \pm 0.2$ & $5.8 \pm 0.6^{\ddagger}$ & $5.9 \pm 0.7^{\ddagger}$ & $5.2 \pm 0.2$ & $5.8 \pm 0.2^{\ddagger}$ & $6.3 \pm 0.3^{ \pm, \pi}$ \\
\hline $\mathrm{HDL}(\mathrm{mg} / \mathrm{dl})$ & $62.0 \pm 19.0$ & $48.6 \pm 14.1^{\ddagger}$ & $41.6 \pm 18.5^{\ddagger}$ & $46.4 \pm 8.9$ & $63.4 \pm 13.1^{\ddagger}$ & $56.8 \pm 12.1^{*}$ \\
\hline LDL (mg/dl) & $107.1 \pm 30.0$ & $110.6 \pm 28.5$ & $136.5 \pm 26.8^{ \pm, \pi}$ & $90.5 \pm 17.0$ & $124.5 \pm 20.5^{\ddagger}$ & $127.6 \pm 33.3^{\ddagger}$ \\
\hline IL-6 (pg/ml) & $0.87 \pm 1.3$ & $3.67 \pm 3.3^{\ddagger}$ & $5.11 \pm 2.5^{\ddagger, \S}$ & $1.01 \pm 0.8$ & $3.17 \pm 2.7^{*}$ & $4.7 \pm 3.0^{\ddagger}$ \\
\hline Adiponectin $(\mu \mathrm{g} / \mathrm{ml})$ & $9.7 \pm 5.0$ & $6.7 \pm 3.9^{\dagger}$ & $4.8 \pm 3.0^{\ddagger}$ & $8.7 \pm 2.5$ & $3.4 \pm 1.2^{\ddagger}$ & $3.5 \pm 1.9^{\ddagger}$ \\
\hline $\mathrm{VO}_{2} \max (\mathrm{ml} / \mathrm{kg}$ per min) & $27.7 \pm 5.7$ & $24.2 \pm 4.4^{\dagger}$ & $23.0 \pm 5.6^{\ddagger}$ & $33.8 \pm 3.4$ & $25.2 \pm 2.3^{\ddagger}$ & $21.8 \pm 3.2^{\ddagger, \|}$ \\
\hline
\end{tabular}

Data are expressed as means \pm S.D. and were compared using ANOVA with Bonferroni corrections for post-hoc tests.

${ }^{\star} P<0.05,{ }^{\dagger} P<0.01,{ }^{\ddagger} P<0.001$ versus lean or NGT; ${ }^{\S} P<0.05, " ~ P<0.01,{ }^{\natural} P<0.001$ versus SC fat or IGT. 
analyses in the subgroups of lean (BMI $<25 \mathrm{~kg} / \mathrm{m}^{2}$ ) and obese (BMI $>30 \mathrm{~kg} / \mathrm{m}^{2}$ ) subjects. Based on CT scan measurement (L4-L5) of abdominal visceral and SC fat areas, obese subjects were further categorized as predominantly viscerally or subcutaneously obese. Predominantly visceral obesity was defined as a ratio of visceral/SC fat area $>0.5$ as described previously (16). PPAR $\gamma$ mRNA expression in adipose tissue was not significantly different between omental and SC fat depots in both lean and obese individuals (Fig. 1A). In obese subjects, omental and SC PPAR $\gamma$ mRNA expression was significantly higher than that in lean subjects (Fig. 1A). In addition, individuals with predominantly visceral fat accumulation showed significantly higher PPAR $\gamma$ mRNA expression in both depots compared to SC obese patients (Fig. 1A). Despite significantly lower mRNA expression of PGC- $1 \alpha$ than of PPAR $\gamma$ in adipose tissue, SC PGC- $1 \alpha$ expression was three to fourfold higher than omental PGC-1 $\alpha$ expression in all obesity and fat distribution subclasses (Fig. 1B). In addition, SC PGC-1 $\alpha$ expression was significantly lower in obese patients than in lean controls $(P<0.05$, Fig. 1B). Patients with visceral obesity had significantly lower visceral $P G C-1 \alpha$ expression than lean subjects $(P<0.05$, Fig. 1B).

We then examined age-, gender-, and BMI-adjusted associations of PPAR $\gamma$ and PGC- $1 \alpha$ expression in adipose tissue with anthropometric and metabolic variables among the 153 subjects enrolled in the cross-sectional study (Supplementary Table 1, see section on supplementary data given at the end of this article). Both visceral and SC PPAR $\gamma$ mRNA expression significantly correlated with whole body glucose uptake during the steady state of euglycemic-hyperinsulinemic clamp and HbAlc (Fig. 1C-F). In addition, PPAR $\gamma$ mRNA expression significantly correlated with the parameters of fat distribution (WHR, waist circumference, Supplementary Table 1), glucose metabolism (fasting plasma glucose, 2-h OGTT glucose, Supplementary Table 1), and lipid metabolism (total and low-density lipoprotein (LDL) cholesterol, Supplementary Table 1) as well as with adipose tissue mRNA expression of PPAR $\gamma$ target genes LPL, HSL, and FASN (Supplementary Table 1). There were significant negative
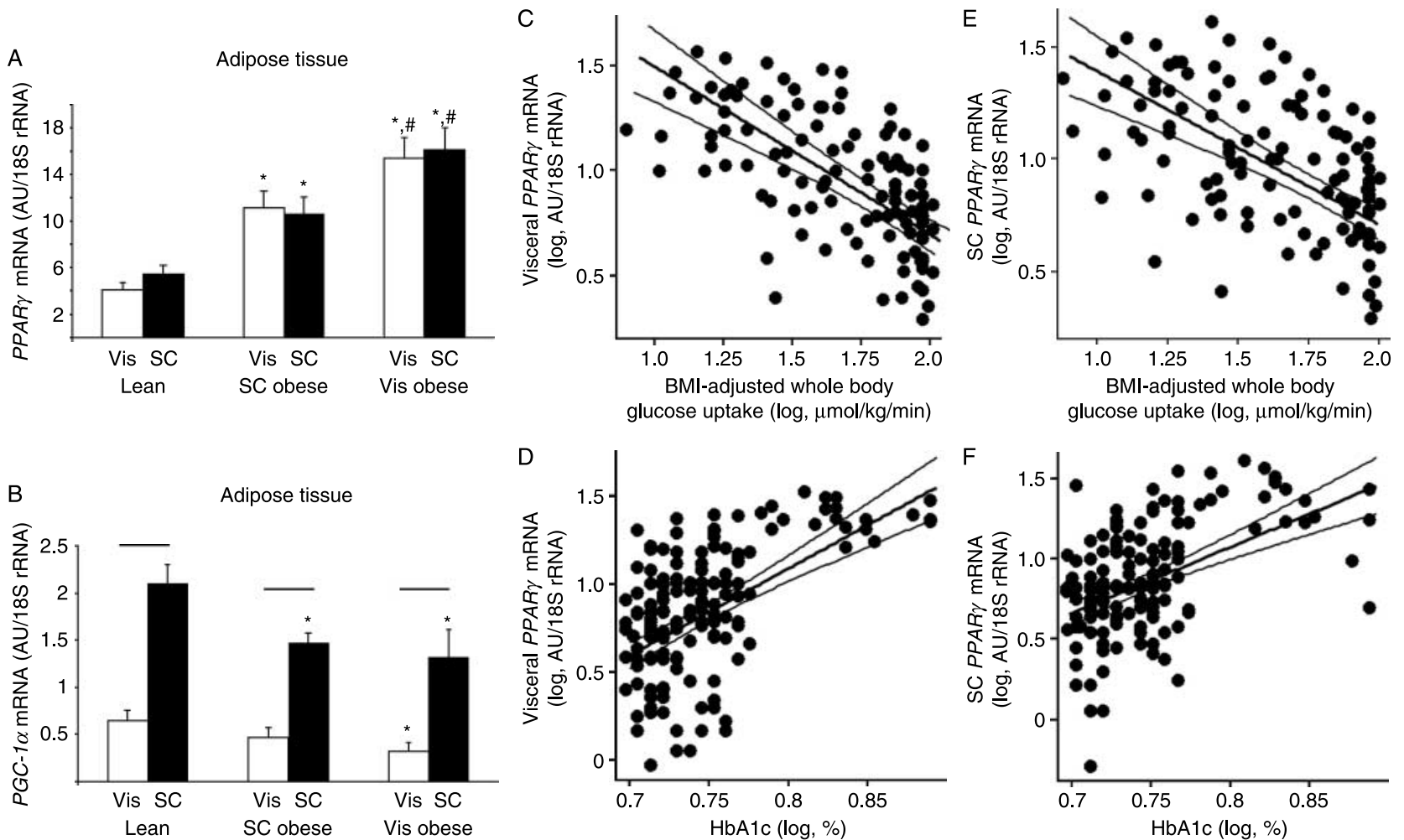

Figure $1 P P A R \gamma$ and $P G C$ - $1 \alpha$ mRNA expression in human adipose tissue. (A) $P P A R \gamma$ and (B) $P G C$ - $1 \alpha$ mRNA expression in visceral (Vis) and subcutaneous (SC) adipose tissue in lean $(n=58)$, predominantly viscerally obese $(n=58)$, or subcutaneously obese ( $n=37)$ subjects. Values are means \pm S.E.M. ${ }^{\star} P<0.05$ for differences between the obesity groups and lean subjects for either omental or subcutaneous fat depot. ${ }^{\#} P<0.05$ for viscerally versus SC obese for either depot. $-P<0.01$ visceral versus SC $P G C-1 \alpha$ mRNA expression.

Correlation between visceral adipose tissue PPAR $\mathrm{mRNA}$ expression and $(\mathrm{C})$ whole body glucose uptake during the steady state of a euglycemic-hyperinsulinemic clamp, adjusted for age, gender, and BMI $(r=-0.61, P<0.001)$ and $(\mathrm{D}) \mathrm{HbA1c}\left(r^{2}=0.64, P<0.001\right)$. Correlation between subcutaneous (SC) adipose tissue $P P A R \gamma$ mRNA expression and (E) whole body glucose uptake during the steady state of a euglycemic-hyperinsulinemic clamp, adjusted for age, gender, and $\mathrm{BMI}(r=-0.47, P<0.01)$ and $(\mathrm{F}) \mathrm{HbA} 1 \mathrm{c}(r=0.49, P<0.01)$. Data are log transformed to achieve normal distribution. 
correlations between PPAR $\gamma$ mRNA expression in both fat depots and adiponectin serum concentration (Supplementary Table 1).

$P G C-1 \alpha$ expression in visceral fat was significantly correlated with adiponectin and percent body fat (negative relationship; Supplementary Table 1). SC PGC-1 $\alpha$ expression correlated with circulating adiponectin, serum FFAs, leptin, and IL-6 concentrations (Supplementary Table 1). For all the above-mentioned parameters, the same correlation patterns (at different significance levels) persisted when adjusting for age, gender, and percent body fat or WHR (data not shown).

\section{SC adipose tissue and skeletal muscle PPAR $\gamma$ and PGC-1 $\propto$ mRNA expression in response to 4 weeks of intensive exercise training}

Sixty Caucasian men and women completed a 4-week training program and were studied after being divided into subgroups with NGT $(n=20)$, IGT $(n=20)$, or T2D $(n=20$; Table 1$)$. The training effect was confirmed by a significant improvement in $\mathrm{VO}_{2}$ max in all groups. As determined by matched paired $t$-test $(P<0.05)$, all subjects had a significant increase in $\mathrm{VO}_{2}$ max after the training period (Fig. 2A). In addition, we observed significant increased adiponectin serum concentrations after the training program in all the glucose tolerance groups (Fig. 2B). Four weeks of physical training resulted in significant decreases in BMI, WHR, and percent body fat in all glucose tolerance groups, and insulin sensitivity significantly improved in the IGT and T2D groups as described previously (17).
PPAR $\gamma$ mRNA expression in skeletal muscle was 1.5-fold higher in subjects with NGT than in subjects with IGT $(P=0.15)$ and was 4.2 -fold higher in subjects with NGT than in patients with T2D $(P<0.001)$. PGC- $1 \alpha$ mRNA expression in skeletal muscle was 1.3-fold higher in subjects with NGT than in subjects with IGT $(P<0.05)$ and was 3.3 -fold higher in subjects with NGT than in patients with T2D $(P<0.001)$. We found age-, gender-, and BMI-adjusted associations of PPAR $\gamma$ and PGC- $1 \alpha$ expression in muscle with anthropometric and metabolic variables among the 60 subjects enrolled in the interventional study (Supplementary Table 1). PPAR $\gamma$ mRNA expression in muscle significantly correlated with the parameters of glucose metabolism (fasting plasma glucose, 2-h OGTT glucose, Supplementary Table 1) and lipid metabolism (total and LDL cholesterol, Supplementary Table 1), but in an opposite direction than in the visceral fat tissue. PGC-1 $\alpha$ expression in muscle was significantly correlated with WHR and with the parameters of insulin sensitivity such as whole body glucose uptake during the steady state of euglycemic-hyperinsulinemic clamp and adiponectin serum concentration (Supplementary Table 1). For all the above-mentioned parameters, the same correlation patterns (at different significance levels) persisted when adjusting for age, gender, and percent body fat or WHR (data not shown).

Skeletal muscle PPAR $\gamma$ mRNA expression significantly increased between 2.3-fold in the T2D group and 1.5-fold in the IGT group in response to the 4-week training program (Fig. 2C). Expression of PPAR $\gamma$ in SC adipose tissue increased in a parallel pattern in all the three groups (Fig. 2D). Changes in SC adipose tissue
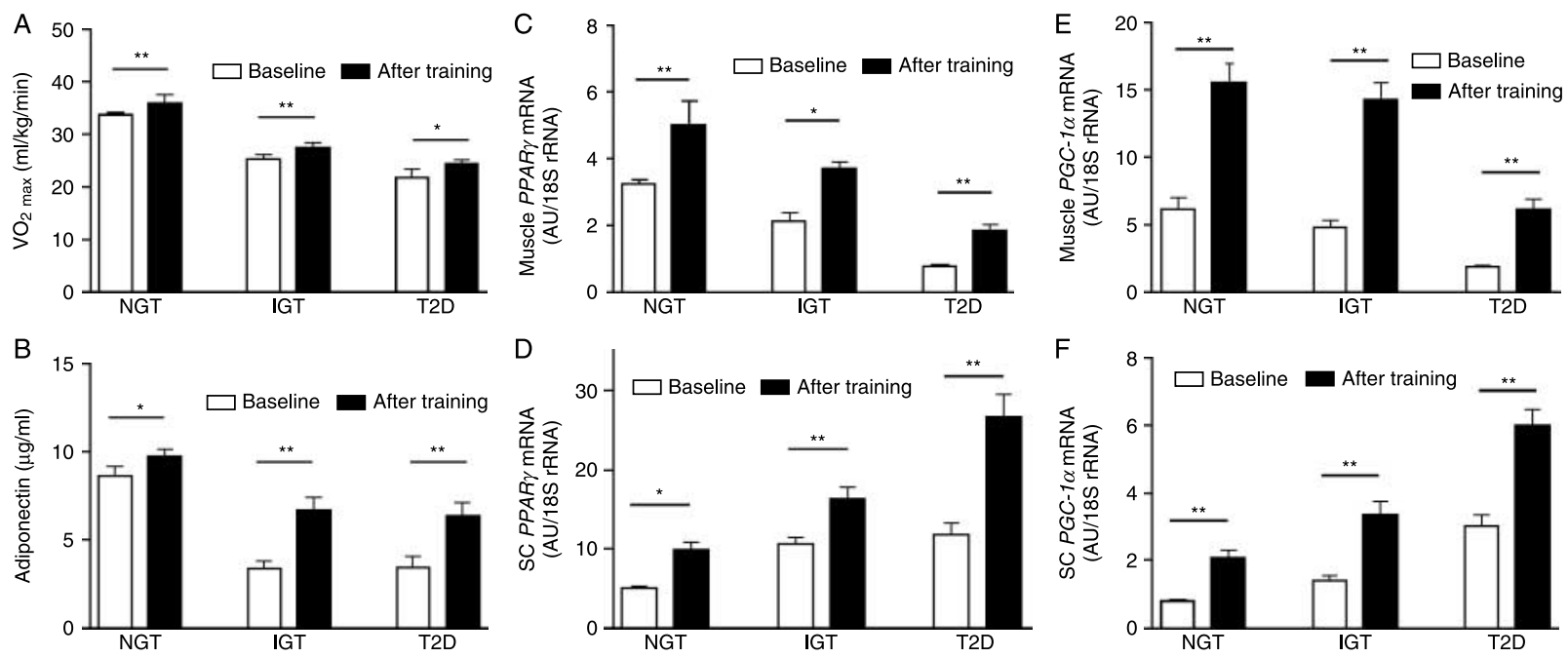

Figure 2 Effect of 4 weeks of intensive exercise program on skeletal muscle and subcutaneous (SC) adipose tissue $P P A R \gamma$ and $P G C$ - $1 \alpha$ mRNA expression in normal glucose-tolerant (NGT) individuals and patients with impaired glucose tolerance (IGT) or type 2 diabetes (T2D). (A) $\mathrm{VO}_{2}$ max, (B) adiponectin serum concentration, (C) skeletal muscle PPAR $\gamma$ mRNA, (D) SC adipose tissue PPAR mRNA, (E) skeletal muscle PGC-1 $\alpha$ mRNA, (F) SC adipose tissue PGC-1 $\alpha$ mRNA in groups of NGT $(n=20)$, IGT $(n=20)$, and T2D ( $n=20)$ before and 4 weeks after an intensive exercise program. Data are means \pm S.E.M. ${ }^{\star} P<0.01,{ }^{\star \star} P<0.001$ between baseline and after 4 weeks of intensive physical training. 
PPAR $\gamma$ mRNA expression significantly correlated with changes in the mRNA expression of PPAR $\gamma$ target genes LPL $(r=0.22, P<0.05)$, HSL $(r=0.19, P<0.05)$, and FASN $(r=0.3, P<0.01)$.

$P G C-1 \alpha$ expression significantly increased in all the three glucose tolerance groups by $\sim 3$-fold in muscle and by $\sim 2$-fold in adipose tissue upon physical exercise (Fig. 2E and F).

\section{Discussion}

Alterations in fatty acid metabolism and mitochondrial dysfunction are critical in the pathogenesis of insulin resistance and the development of T2D. PPAR $\gamma$ and the transcriptional coactivator PGC- $1 \alpha$ are pivotal in these pathways because they control genes involved in fatty acid oxidation and mitochondrial respiratory chain (1, 5). Mootha et al. (20) identified a set of genes involved in OXPHOS, the expression of which was coordinately decreased in human diabetic muscle. Similarly, Patti et al. (8) found the downregulation of OXPHOS not only in individuals with T2D, but also in their first-degree relatives. In both these studies, decreased PPAR $\gamma$ and PGC-1 $\alpha$ expression was responsible for the downregulation of OXPHOS genes. In addition, the expression of PGC- $1 \alpha$ has been shown to be downregulated in adipose tissue of insulin-resistant (3) and morbidly obese (4) subjects.

Here, we extended the previous findings by systematically analyzing the anthropometric and metabolic correlates of adipose tissue and skeletal muscle $P P A R \gamma$ and PGC- $1 \alpha$ mRNA expression in individuals with a wide range of BMI, fat mass, glucose tolerance, and insulin sensitivity both in a cross-sectional study including paired visceral and SC gene expression and in an exercise intervention study. Our study extends a previous pilot study (3) and looks at the metabolic parameters and inflammatory markers in association with the simultaneous measurement of muscle and adipose tissue expression of PGC- $1 \alpha$ and $P P A R \gamma$ in a large study of, collectively, more than 200 individuals. First, we confirmed the recent findings that the expression of PPAR $\gamma$ is not different between omental and SC fat depots $(21,22)$. It was shown previously that the expression of PPAR $\gamma_{1}$ is fat depot specific, whereas that of $P P A R \gamma_{2}$ is indistinguishable between omental and SC fat (23). Since our adipose tissue mRNA analysis measured $\operatorname{PPAR} \gamma_{2}$, our results are in accordance with the previous report (23). Noteworthily, the major PPAR $\gamma$ isoform in nonadipose tissue is PPAR $\gamma_{1}$. We therefore measured $P P A R \gamma_{1}$ mRNA expression in skeletal muscle biopsies. We found opposite gene expression patterns for adipose tissue PPAR $\gamma$ and $P G C-1 \alpha$ mRNA expression. The gene expression of $P P A R \gamma$ in both omental and SC adipose tissues significantly correlates with increasing body weight, fat mass, parameters of impaired glucose metabolism, and insulin sensitivity. Noteworthily, strong negative correlations have been found between visceral and SC PPAR $\gamma$ expression and the whole body glucose uptake during the steady state of euglycemic-hyperinsulinemic clamps. Increasing adipose tissue $P P A R \gamma$ expression may represent a compensatory mechanism for the organism in response to the deterioration of insulin sensitivity and glucose metabolism. Our data are in accordance with a recent report, demonstrating significantly upregulated PPAR $\gamma$ mRNA expression in the mesenteric adipose tissue of diabetic patients (24). In addition, we confirmed the first reported positive association between PPAR $\gamma$ expression and parameters of obesity and impaired glucose metabolism (25). Although Dubois et al. (26) showed significantly lower adipose tissue PPAR $\gamma$ expression in obese patients with T2D than in patients without diabetes, they (26) did not include lean healthy controls. We found a significant positive association between PPAR $\gamma$ expression in adipose tissue and BMI, waist circumference, and WHR, whereas a previous report showed the opposite direction of these correlations in obese women (23).

In contrast to the observations in adipose tissue, our data demonstrate opposite relationships between $P P A R \gamma$ expression in skeletal muscle and metabolic parameters. In muscle, expression of PPAR $\gamma$ decreases with the impairment of glucose tolerance and insulin sensitivity. For example, there were negative correlations between muscle $P P A R \gamma$ expression, fasting plasma glucose, and total and LDL cholesterol. Our data support the notion that efficient mitochondrial metabolism and energy utilization, which are both directly linked to the expression of $P P A R \gamma$, are compromised in insulin-resistant states and in patients with T2D (20).

Importantly, we have also shown here that 4 weeks of intensive exercise training significantly increases $P P A R \gamma$ mRNA expression in skeletal muscle independently of different glucose tolerance subgroups. We have shown here for the first time that increased PPAR $\gamma$ mRNA in muscle is paralleled by significantly increased $P P A R \gamma$ mRNA expression in SC adipose tissue. Our data are in accordance with the recently reported general upregulation of PPAR $\gamma$ mRNA in several tissues of rats (27).

However, PPAR $\gamma$ mRNA expression does only in part determine its activity, and post-transcriptional modulation and binding of nuclear cofactors certainly play an important role in PPAR $\gamma$ activation $(28,29)$. To address this limitation of our study, we measured adipose tissue mRNA of confirmed PPAR $\gamma$ target genes, LPL, HSL, and FASN, both in the cross-sectional study and in the interventional study. This gene selection was based on results demonstrating that activation of PPAR $\gamma$ by thiazolidinedione treatment causes significant increase in adipose tissue expression of FASN, LPL (30) and HSL (31). 
At baseline, we found significant correlations between PPAR $\gamma$ mRNA expression and FASN, HSL, and LPL mRNA expression in both fat depots. Moreover, increased expression of PPAR $\gamma$ in SC adipose tissue 4 weeks after the exercise training program significantly correlated with changes in LPL, HSL, and FASN adipose tissue mRNA expression, suggesting that increased $P P A R \gamma$ mRNA expression in response to training may be of functional relevance for the expression of its target genes.

Analysis of $P G C-1 \alpha$ mRNA expression in human adipose tissue revealed significantly higher $P G C-1 \alpha$ expression in SC adipose tissue than in omental adipose tissue independently of obesity and fat distribution. This is in contrast to a previous study, which did not find significant fat depot-specific expression of $P G C-1 \alpha$ (4). In addition, we found significantly decreased PGC-1 $\alpha$ mRNA expression with increasing body fat mass, visceral fat distribution, and impaired glucose metabolism. Our data confirm and extend previous results demonstrating reduced PGC- $1 \alpha$ mRNA expression in adipose tissue in patients with obesity and insulin resistance $(3,4)$. PGC-1 $\alpha$ mRNA expression of both omental and SC adipose tissues positively correlates with circulating adiponectin, suggesting that PGC-1 $\alpha$ may play a role in adiponectin secretion. This hypothesis is further supported by recent data showing an association of the PGC-1 $\alpha$ Gly482Ser polymorphism with circulating adiponectin in patients with diabetes (32).

In parallel to the observed increase in skeletal muscle PPAR $\gamma$ mRNA expression upon physical training, we found that 4 weeks of intensive exercise training significantly increases $P G C-1 \alpha$ mRNA expression in skeletal muscle and simultaneously in SC adipose tissue independently of different glucose tolerance subgroups. Our study is the first to demonstrate increased PGC-1 $\alpha$ mRNA expression in adipose tissue upon physical training despite relatively low baseline PGC- $1 \alpha$ mRNA expression in adipose tissue. Previous work has suggested that intensive exercise leads to increased levels of PGC-1 $\alpha$ expression in muscle of mice (33) and healthy male human subjects $(9,10)$. However, two recent studies looked specifically at $P G C-1 \alpha$ expression in human muscle after exercise and found somewhat conflicting results $(13,14)$. Heilbronn et al. (14) found unchanged $P G C-1 \alpha$ expression in muscle after a 6 -week training program. Differences in the study population, training intensity, and timing of muscle biopsies (36 vs $48 \mathrm{~h}$ post exercise in our study) may contribute to the divergent results. Our data of increased $P G C-1 \alpha$ expression in muscle are in accordance with another recent report that acute exercise increases $P G C-1 \alpha$ expression despite a delayed response in obese patients (13). It has been shown that PGC-1 $\alpha$ is preferentially expressed in muscle enriched for slow oxidative type I fibers (5). In this context, we could show previously that reduced oxidative enzyme activity in muscle of type 2 diabetic patients is most likely due to a reduction in slow oxidative fibers (34). Therefore, reduced PGC-1 $\alpha$ expression in muscle of patients with IGT or T2D may be due to altered muscle fiber distribution with impaired glucose metabolism. Noteworthily, upregulation of PGC- $1 \alpha$ in the muscle of transgenic mice in vivo was shown to be sufficient to improve exercise performance under different exercise paradigms as well as to increase peak oxygen uptake (33). This suggests that increased muscle $P G C-1 \alpha$ expression in response to physical training may mediate the beneficial effects of exercise on insulin sensitivity. How does exercise regulate the expression of transcription factors? In relation to exercise, potential stimuli include stretch and muscle tension, the pattern of motor nerve activity and the resultant calcium transients, the energy charge of the cell and substrate availability, oxygen tension, and circulating hormones (35). Exercise training leads to skeletal muscle fiber-type transformation, mitochondrial biogenesis, and increased GLUT4 protein expression (36). Muscle contractions lead to rapid and robust increases in the activation of signaling factors within skeletal muscle cells, representing the initial step in the exercise-induced regulation of gene expression (37). Recently, Röckl et al. proposed a model on how different signaling pathways may be involved in these training-related adaptations (36). Changes in the cellular energy status stimulate AMP-activated protein kinase in the presence of the AMPK, LKB1. AMPK may be involved in exercise-related muscle adaptation through increasing $P G C-1 \alpha$ expression, which is potentiated by a positive feedback loop through myocyte-enhancing factor-2. Alternative pathways by which exercise may regulate the expression of $P G C-1 \alpha$ are contraction-induced activation of p38 MAPK and increased intracellular $\mathrm{Ca}^{2+}$ levels leading to the activation of the $\mathrm{Ca}^{2+} /$ calmodulin-dependent phosphatase, and calcineurin, as well as of $\mathrm{Ca}^{2+} /$ calmodulindependent protein kinases (36).

Some limitations of our study need to be discussed. We recognize the potential for uncontrolled confounding of a large cross-sectional study, and that observational studies do not address causality or mechanisms. Nevertheless, they are useful for developing hypotheses for further research using interventions such as the one used in the second part of our study. Although we examined 4 weeks of intensive exercise in the largest study to date, future studies are needed to examine other interventions including dietary and/or pharmacological interventions. Information regarding medication used by our subjects is not known. Finally, we recognize that our interventional study group was of a relatively small size; nevertheless, our results correlate with other published data and support our hypothesis that gene expression of PPAR $\gamma$ and PGC-1 $\alpha$ in muscle increases with intensive physical exercise. Taken together, our data suggest that PPAR $\gamma$ and $P G C-1 \alpha$ expression in muscle is directly associated with changes 
in metabolic parameters, implying a direct and possibly causal role of these molecules in the regulation of these parameters. In contrast, expression of PPAR $\gamma$ and $P G C-1 \alpha$ in fat is apparently compensatory.

In conclusion, gene expression of PPAR $\gamma$ and PGC- $1 \alpha$ in human adipose tissue is related to fat mass, fat distribution and markers of insulin resistance, glucose tolerance, adipose tissue function, and inflammation. Increased muscle and adipose tissue PPAR $\gamma$ and $P G C-1 \alpha$ expression in response to physical training may mediate the beneficial effects of exercise on insulin sensitivity.

\section{Supplementary data}

This is linked to the online version of the paper at http://dx.doi.org/10. 1530/EJE-09-0767.

\section{Declaration of interest}

The authors declare that there is no conflict of interest that could be perceived as prejudicing the impartiality of the research reported.

\section{Funding}

This work was supported by grants from Deutsche Forschungsgemeinschaft (DFG): Clinical Research group 'Atherobesity' KFO 152 (project BL 833/1-1 to MB and project FA 476/4-1 to MF); NIH grants DK58785, DK79929, DK 081913 and DK58845; and a discretionary grant from BIDMC.

\section{References}

1 Puigserver P \& Spiegelman BM. Peroxisome proliferator-activated receptor-gamma coactivator 1 alpha (PGC-1 alpha): transcriptional coactivator and metabolic regulator. Endocrine Reviews 200324 78-90.

2 Pirinen E, Kuulasmaa T, Pietilä M, Heikkinen S, Tusa M, Itkonen P, Boman S, Skommer J, Virkamäki A, Hohtola E, Kettunen M, Fatrai S, Kansanen E, Koota S, Niiranen K, Parkkinen J, Levonen AL, Ylä-Herttuala S, Hiltunen JK, Alhonen L, Smith U, Jänne J \& Laakso M. Enhanced polyamine catabolism alters homeostatic control of white adipose tissue mass, energy expenditure, and glucose metabolism. Molecular and Cellular Biology 200727 4953-4967.

3 Hammarstedt A, Jansson PA, Wesslau C, Yang X \& Smith U. Reduced expression of PGC-1 and insulin-signaling molecules in adipose tissue is associated with insulin resistance. Biochemical and Biophysical Research Communications 2003301 578-582.

4 Semple RK, Crowley VC, Sewter CP, Laudes M, Christodoulides C, Considine RV, Vidal-Puig A \& O'Rahilly S. Expression of the thermogenic nuclear hormone receptor coactivator PGC-1alpha is reduced in the adipose tissue of morbidly obese subjects. International Journal of Obesity and Related Metabolic Disorders 200428 176-179.

5 Lin J, Wu H, Tarr PT, Zhang CY, Wu Z, Boss O, Michael LF, Puigserver P, Isotani E, Olson EN, Lowell BB, Bassel-Duby R \& Spiegelman BM. Transcriptional co-activator PGC-1 alpha drives the formation of slow-twitch muscle fibres. Nature 2002 418 797-801.

6 Ling C, Poulsen P, Carlsson E, Ridderstråle M, Almgren P, Wojtaszewski J, Beck-Nielsen H, Groop L \& Vaag A. Multiple environmental and genetic factors influence skeletal muscle $P G C-1 \alpha$ and PGC-1 $\beta$ gene expression in twins. Journal of Clinical Investigation $20041141518-1526$.

7 Attie AD \& Kendziorski CM. PGC-1alpha at the crossroads of type 2 diabetes. Nature Genetics 200334 244-245.

8 Patti ME, Butte AJ, Crunkhorn S, Cusi K, Berria R, Kashyap S, Miyazaki Y, Kohane I, Costello M, Saccone R, Landaker EJ, Goldfine AB, Mun E, DeFronzo R, Finlayson J, Kahn CR \& Mandarino LJ. Coordinated reduction of genes of oxidative metabolism in humans with insulin resistance and diabetes: potential role of PGC1 and NRF1. PNAS 2003100 8466-8471.

9 Russell AP, Feilchenfeldt J, Schreiber S, Praz M, Crettenand A, Gobelet C, Meier CA, Bell DR, Kralli A, Giacobino JP \& Dériaz O. Endurance training in humans leads to fiber type specific increases in levels of peroxisome proliferator activated receptor gamma coactivator 1 and peroxisome proliferator activated receptor alpha in skeletal muscle. Diabetes 200352 2874-2881.

10 Pilegaard H, Saltin B \& Neufer PD. Exercise induces transient transcriptional activation of the PGC-1alpha gene in human skeletal muscle. Journal of Physiology $2003 \mathbf{5 4 6}$ 851-858.

11 Gibala MJ, McGee SL, Garnham AP, Howlett KF, Snow RJ \& Hargreaves M. Brief intense interval exercise activates AMPK and p38 MAPK signaling and increases the expression of PGC- $1 \alpha$ in human skeletal muscle. Journal of Applied Physiology 2009106 929-934.

12 Mortensen OH, Plomgaard P, Fischer CP, Hansen AK, Pilegaard H \& Pedersen BK. PGC-1beta is downregulated by training in human skeletal muscle: no effect of training twice every second day vs. once daily on expression of the PGC-1 family. Journal of Applied Physiology 2007103 1536-1542.

13 De Filippis E, Alvarez G, Berria R, Cusi K, Everman S, Meyer C \& Mandarino LJ. Insulin-resistant muscle is exercise resistant: evidence for reduced response of nuclear-encoded mitochrondrial genes to exercise. American Journal of Physiology. Endocrinology and Metabolism 2008294 607-614.

14 Heilbronn LK, Gan SK, Turner N, Campbell LV \& Chisholm DJ. Markers of mitochondrial biogenesis and metabolism are lower in overweight and obese insulin resistant subjects. Journal of Clinical Endocrinology and Metabolism 200792 1467-1473.

15 Youn BS, Bang SI, Klöting N, Park JW, Lee N, Oh JE, Pi KB, Lee TH, Ruschke K, Fasshauer M, Stumvoll M \& Blüher M. Serum progranulin concentrations may be associated with macrophage infiltration into omental adipose tissue. Diabetes $2009 \mathbf{5 8}$ 627-636.

16 Blüher M, Williams CJ, Klöting N, Hsi A, Ruschke K, Oberbach A, Fasshauer M, Berndt J, Schön MR, Wolk A, Stumvoll M \& Mantzoros CS. Gene expression of adiponectin receptors in human visceral and subcutaneous adipose tissue is related to insulin resistance and metabolic parameters and is altered in response to physical training. Diabetes Care 200730 3110-3115.

17 Blüher M, Bullen JW Jr, Lee JH, Kralisch S, Fasshauer M, Klöting N, Niebauer J, Schön MR, Williams CJ \& Mantzoros CS. Circulating adiponectin and expression of adiponectin receptors in human skeletal muscle: associations with metabolic parameters and insulin resistance and regulation by physical training. Journal of Clinical Endocrinology and Metabolism 200691 2310-2316.

18 Berndt J, Kralisch S, Klöting N, Ruschke K, Kern M, Fasshauer M, Schön MR, Stumvoll M \& Blüher M. Adipose triglyceride lipase gene expression in human visceral obesity. Experimental and Clinical Endocrinology and Diabetes 2008116 203-210.

19 Berndt J, Kovacs P, Ruschke K, Klöting N, Fasshauer M, Schön MR, Körner A, Stumvoll M \& Blüher M. Fatty acid synthase gene expression in human adipose tissue: association with obesity and type 2 diabetes. Diabetologia 200750 1472-1480.

20 Mootha VK, Lindgren CM, Eriksson KF, Subramanian A, Sihag S, Lehar J, Puigserver P, Carlsson E, Ridderstråle M, Laurila E, Houstis N, Daly MJ, Patterson N, Mesirov JP, Golub TR, Tamayo P, Spiegelman B, Lander ES, Hirschhorn JN, Altshuler D \& Groop LC. PGC- $1 \alpha$ responsive genes involved in oxidative phosphorylation are coordinately downregulated in human diabetes. Nature Genetics 200334 267-273. 
21 Montague CT, Prins JB, Sanders L, Zhang J, Sewter CP, Digby J, Byrne CD \& O'Rahilly S. Depot-related gene expression in human subcutaneous and omental adipocytes. Diabetes $1998 \mathbf{4 7}$ 1384-1391.

22 Bortolotto JW, Margis R, Ferreira AC, Padoin AV, Mottin CC \& Guaragna RM. Adipose tissue distribution and quantification of PPARbeta/delta and PPARgamma1-3 mRNAs: discordant gene expression in subcutaneous, retroperitoneal and visceral adipose tissue of morbidly obese patients. Obesity Surgery 2007 17 934-940.

23 Giusti V, Verdumo C, Suter M, Gaillard RC, Burckhardt P \& Pralong F. Expression of peroxisome proliferator-activated receptor-gamma1 and peroxisome proliferator-activated receptorgamma 2 in visceral and subcutaneous adipose tissue of obese women. Diabetes 200352 1673-1676.

24 Yang YK, Chen M, Clements RH, Abrams GA, Aprahamian CJ \& Harmon CM. Human mesenteric adipose tissue plays unique role versus subcutaneous and omental fat in obesity related diabetes. Cellular Physiology and Biochemistry 200822 531-538.

25 Vidal-Puig AJ, Considine RV, Jimenez-Liñan M, Werman A, Pories WJ, Caro JF \& Flier JS. Peroxisome proliferator-activated receptor gene expression in human tissues. Effects of obesity, weight loss, and regulation by insulin and glucocorticoids. Journal of Clinical Investigation $1997992416-2422$.

26 Dubois SG, Heilbronn LK, Smith SR, Albu JB, Kelley DE, Ravussin E \& Look AHEAD Adipose Research Group. Decreased expression of adipogenic genes in obese subjects with type 2 diabetes. Obesity $2006141543-1552$.

27 Kawamura T, Yoshida K, Sugawara A, Nagasaka M, Mori N, Takeuchi K \& Kohzuki M. Regulation of skeletal muscle peroxisome proliferator-activated receptor gamma expression by exercise and angiotensin-converting enzyme inhibition in fructose-fed hypertensive rats. Hypertension Research 200427 61-70.

28 Auwerx J. PPARgamma, the ultimate thrifty gene. Diabetologia 199942 1033-1049.

29 Lefterova MI, Zhang Y, Steger DJ, Schupp M, Schug J, Cristancho A, Feng D, Zhuo D, Stoeckert CJ Jr, Liu XS \& Lazar MA. PPARgamma and C/EBP factors orchestrate adipocyte biology via adjacent binding on a genome-wide scale. Genes and Development 200822 2941-2952.
30 Bogacka I, Xie H, Bray GA \& Smith SR. The effect of pioglitazone on peroxisome proliferator-activated receptor-gamma target genes related to lipid storage in vivo. Diabetes Care 200427 1660-1667.

31 Deng T, Shan S, Li PP, Shen ZF, Lu XP, Cheng J \& Ning ZQ. Peroxisome proliferator-activated receptor-gamma transcriptionally up-regulates hormone-sensitive lipase via the involvement of specificity protein-1. Endocrinology $2006 \mathbf{1 4 7} 875-884$.

32 Okauchi Y, Iwahashi H, Okita K, Yuan M, Matsuda M, Tanaka T, Miyagawa J, Funahashi T, Horikawa Y, Shimomura I \& Yamagata K. PGC-1alpha Gly482Ser polymorphism is associated with the plasma adiponectin level in type 2 diabetic men. Endocrine Journal 200855 991-997.

33 Calvo JA, Daniels TG, Wang X, Paul A, Lin J, Spiegelman BM, Stevenson SC \& Rangwala SM. Muscle specific expression of PPAR $\gamma$ coactivator- $1 \alpha$ improves exercise performance and increases peak oxygen uptake. Journal of Applied Physiology 2008 104 1304-1324.

34 Oberbach A, Bossenz Y, Lehmann S, Niebauer J, Adams V, Paschke R, Schön MR, Blüher M \& Punkt K. Altered fiber distribution and fiber-specific glycolytic and oxidative enzyme activity in skeletal muscle of patients with type 2 diabetes. Diabetes Care 200629 895-900.

35 Hargreaves M \& Cameron-Smith D. Exercise, diet, and skeletal muscle gene expression. Medicine and Science in Sports and Exercise 200234 1505-1508.

36 Röckl KS, Witczak CA \& Goodyear LJ. Signaling mechanisms in skeletal muscle: acute responses and chronic adaptations to exercise. IUBMB Life 200860 145-153.

37 Benton CR, Wright DC \& Bonen A. PGC-1alpha-mediated regulation of gene expression and metabolism: implications for nutrition and exercise prescriptions. Applied Physiology, Nutrition, and Metabolism 200833 843-862.

Received 14 November 2009

Accepted 3 December 2009 